\title{
A CONCEPT FOR THE EXAMINATION OF REFERENCE POINTS STABILITY IN HORIZONTAL CONTROL NETWORKS
}

\author{
Ryszard Malarski \\ Warsaw University of Technology, \\ Faculty of Geodesy and Cartography \\ Department of Engineering Geodesy and Control Surveying Systems
}

\begin{abstract}
This paper presents a concept for the identification of stable reference points used in horizontal control networks, which is based on the lengths of apparent displacement vectors and their mean errors. These vectors and their mean errors are obtained during the process of calculating displacements with free adjustment conditions. It will be shown that the influence of the apparent displacement vectors has a significant effect on the calculation of results. The identification of stable points, using the proposed method, is an integral part of the adjustment process and allows for the interrogation the influence of individual point inclusion or deletion from the reference database, on the values of displacements of controlled points. A detailed process of stable reference points identification is presented using the example of a linear-angular network for a barrage.
\end{abstract}

Keywords: calculations of displacements, reference points identification

\section{Introduction}

The process of calculations displacements common adjustment for periodical observations, or their differences with consideration of the free adjustment conditions on a set of reference points, has been widely applied since the middle eighties.

In the case of small horizontal networks, methods have been developed based on investigations the rotation of pairs of points and changes in their lengths to detect groups of mutually stable points (Lazzarini, 1977; Laudyn, 1985).

Unfortunately, the usefulness of these methods becomes less effective in large control networks. In these large horizontal control networks the selection of a method of identifying stable points is connected with definition of conditions, overlaid on a set of reference points.

This paper presents a concept of identifying stable reference points used in horizontal control networks, based on the lengths of apparent displacement vectors 
and their mean errors. These are obtained during the process of calculating displacements with free adjustment conditions. It is important to stress the influence of apparent displacement vectors properties on the calculated results.

The Identification of stable points, performed with the use of the proposed method is an integral part of the adjustment process. This allows an analysis for the inclusion or omission of points into the reference database, based on the values of controlled points displacements.

\section{Properties of vectors of apparent displacements}

The calculation of displacements with free adjustment conditions mostly means the adjustment of differences between observations from initial and current surveys, with conditions which reflect the properties of parameters in Helmert transformation.

Apparent displacements obtained in this process correspond to deviations which would result from Helmert transformation of coordinates, determined from independent adjustment of observations from two cycles of measurements. This can be met under the condition of compliance for the distribution of observation errors in both surveys, as well as in their differences. It is widely known that in the process of creating differences from the initial and current observations, systematic errors are partially removed. Using the example of control networks, developed by the author, it may be stated that in the process of adjusting differences of observations, standard deviations in typical observation were considerably reduced in the majority of cases. However, it may be stated in general that values of displacements, calculated using free adjustment, will be similar to values resulting from Helmert transformation. The advantage of calculating displacements in the process of free adjustment, compared to Helmert transformation, is the possibility to perform the complete accuracy assessment of the determined displacements (Laudyn, 1985).

In the differential method the following relation occurs between observations of the control network from two cycles of measurements:

$$
s_{i}+v_{i}+\Delta s_{i}=s_{i}^{\prime}+v_{i}^{\prime} \text {, }
$$

where: $s_{i}, s_{i}$ - initial and current observation,

$\Delta s_{i}=f\left(\Delta X_{1}, \Delta X_{2}, \ldots, \Delta X_{n+s}\right)$,

$\mathrm{i}=1,2, \ldots \mathrm{r}$, - the number of repeatable observations,

$\Delta \mathrm{X}_{1}, \Delta \mathrm{X}_{2}, \ldots, \Delta \mathrm{X}_{\mathrm{n}+\mathrm{s}}$ - the displacement vectors of points in the network.

In practice, the relation determined by the formula (1) means the parametric method. Considering the relationships:

$$
\mathrm{V}=\mathrm{v}^{\prime}-\mathrm{v} \text { and } \mathrm{L}=-\left(\mathrm{s}^{\prime}-\mathrm{s}\right)
$$

in the system of equations (1), we obtain a typical solution of corrections to differences of observations in the form:

$$
\mathrm{V}=\mathrm{A} \Delta \mathrm{X}+\mathrm{L}
$$

Such equations may be directly created for differences of observations.

The system of equations (2) may be written in a block, dividing the matrix of coefficients of the unknowns $A$ into submatrices $A_{n}$ and $A_{s}$, referring to vectors of displacements of unstable points $\Delta X_{n}$ and reference points $\Delta X_{s}$, respectively:

$$
[V]=\left[A_{n} \mid A_{s}\right]\left[\frac{\Delta X_{n}}{\Delta X_{s}}\right]+[L]
$$


Applying the condition of the minimum sum of squares of corrections to observational differences, i.e. $V^{\top} P V=$ minimum, leads to the system of normal equations and a singular matrix of coefficients. Considering displacements of the socalled free adjustment conditions in the process of calculating displacements, in the form of conditions resulting from the properties of parameters of Helmert transformation, results in the solution which meets the following conditions:

$$
V^{T} P V=\min \text {. and } \Delta X_{S}^{T} \Delta X_{S}=\min .
$$

These conditions, the number of which equals to the number of defects of the network, are commonly known in their general form:

$$
\mathrm{S}_{0} \Delta \mathrm{X}_{\mathrm{S}}=0 \text {. }
$$

These conditions are known as Helmert-Wolf conditions in relation to adjustment of observations in conventional geodetic networks (Świątek and Wiśniewski, 1983).

They have the following form in relation to processing surveys of displacements:

- for angular-and-linear network:

$$
\begin{aligned}
& \sum_{1}^{S} \Delta \mathrm{X}_{\mathrm{S}_{\mathrm{i}}}=0, \\
& \sum_{1}^{S} \Delta \mathrm{Y}_{\mathrm{S}_{\mathrm{i}}}=0, \\
& \sum_{1}^{S}\left[\left(\mathrm{Y}_{\mathrm{S}_{\mathrm{i}}}-\mathrm{Y}_{\mathrm{B}}\right) \Delta \mathrm{X}_{\mathrm{S}_{\mathrm{i}}}-\left(\mathrm{X}_{\mathrm{S}_{\mathrm{i}}}-\mathrm{X}_{\mathrm{B}}\right) \Delta \mathrm{Y}_{\mathrm{S}_{\mathrm{i}}}\right]=0,
\end{aligned}
$$

- for angular network as well:

$$
\sum_{1}^{S}\left[\left(\mathrm{X}_{\mathrm{S}_{\mathrm{i}}}-\mathrm{X}_{\mathrm{B}}\right) \Delta \mathrm{X}_{\mathrm{S}_{\mathrm{i}}}+\left(\mathrm{Y}_{\mathrm{S}_{\mathrm{i}}}-\mathrm{Y}_{\mathrm{B}}\right) \Delta \mathrm{Y}_{\mathrm{S}_{\mathrm{i}}}\right]=0,
$$

where: $X_{B}, Y_{B}$ - coordinates of the pole (centre of gravity).

In order to solve this task, the parametric method with conditions for the unknowns is normally applied. For such task of adjustment, the system of normal equations has the following block form:

$$
\left[\begin{array}{ccc}
A_{n}^{T} P A_{n} & A_{n}^{T} P A_{S} & 0 \\
A_{S}^{T} P A_{n} & A_{S}^{T} P A_{S} & S_{0}^{T} \\
0 & S_{0} & 0
\end{array}\right]\left[\begin{array}{c}
\Delta X_{n} \\
\Delta X_{S} \\
K
\end{array}\right]+\left[\begin{array}{c}
A_{n}^{T} P L \\
A_{S}^{T} P L \\
0
\end{array}\right]=\left[\begin{array}{l}
0 \\
0 \\
0
\end{array}\right]
$$

where: $K$ - vector of correlates,

$\Delta X_{n}, \Delta X_{s}$ - vectors of displacements of unstable points $(n)$ and reference points $(s)$.

The system of normal equations (5), generated as a result of adding the conditional equations, contains the zero main determinants. However, it is symmetrical system on the non-zero basic determinant and therefore has a unique solution.

It is easy to notice that, in the process of calculations performed with consideration of free adjustment conditions, the value of the displacement vector consists of ",0" the displacement of a pole (centre of gravity) and a point displacement in relation to the pole. Therefore, mean errors of the displacement vector are a function of those components and are the so-called positional characteristics of the accuracy.

It turns out from the conditions (4) that the mean errors of "O" components of the pole displacements, calculated using the formula: 


$$
m_{\Delta X_{B}}=m_{\Delta Y_{B}}=\sigma_{0} \sqrt{f\left(\Delta X_{S}\right)^{T}\left(A^{T} P A\right)_{S}^{-} f\left(\Delta X_{S}\right)},
$$

will always be zero, regardless of the value of the apparent displacements reference points.

In the formula (6), $f\left(\Delta X_{S}\right)$ means the vector of partial derivatives of a function which describes the displacements of the pole, and $\left(A^{T} P A\right)_{S}^{-}-$is the submatrix of reverse matrix to the coefficient matrix of the system (5).

Mean errors of components of the vector displacements of the i-th point, are the so-called positional characteristics of the accuracy, which are calculated using the formula:

$$
m_{\Delta_{i}}=\sigma_{0} \sqrt{\left[\left(A^{T} P A\right)_{S}^{-}\right]_{i i}} .
$$

Mean error of the length of a vector depend upon a set of reference points.

The following properties result from conditions (4) and a solution of equations (5):

- sums of components of vector of displacements to reference points, are equal to zero: $\left[\Delta X_{s i}\right]=0,\left[\Delta Y_{s i}\right]=0$,

- values of correlates are equal to zero $\boldsymbol{k}=\mathbf{0}$,

- the displacement of pole is exactly equal to zero,

- mean errors of displacements of the pole are equal to zero:

$$
\boldsymbol{m}_{\Delta X_{B}}=\boldsymbol{m}_{\Delta Y_{B}}=\mathbf{0},
$$

- mean errors of components of the vectors of displacements are calculated in relation to the pole,

- for points located closer to the pole, smaller errors are obtained than in the case for those located farther from the pole,

- the mean rotation of a network related to a set of reference points, proved to be of minor value but not equal to zero.

By using dummy coordinates with a regular distribution of reference points and applying a Helmert transformation, the Author come to the following conclusions:

- coordinates changes of centrally located points, cause the same results in length of transformation residuals for other reference points,

- coordinates changes of points located on the periphery and located in symmetry to the pole, yields a similar amount of change in transformation residuals discrepancies at all reference points,

- changes in coordinate value located away from the central point or on the periphery, but not symmetrical to the pole, causes increase in changes of transformation residuals in proportion to the distance reference points are from the pole.

It may therefore by stated that the length of apparent displacement vectors end it mean errors depends on the point location in relation to the pole.

In the process of identifying stable reference points basing on analysing apparent displacement vectors and their mean errors, properties of such vectors listed above, should be considered.

The error-free pole, resulting from free adjustment conditions, may generate some disputes. The so-called mean adaptation error, resulting from the values of apparent displacements of reference points, is ignored.

Apparent displacements, obtained in the process of calculating displacements based on common free adjustment of periodical observations, are characterised by the same properties which are described above in the adjustment of observational differences. 


\section{The proposed method of investigating the stability of the reference system}

It may be stated that the component vectors of apparent displacements result from the true value of displacements, the accuracy of initial and current surveys, the network geometry and the definition of a reference system.

The development of computer techniques and the graphical presentation of results, has contributed to the development of global, multi-variant analyses of the so-called apparent displacements and their mean errors.

The apparent displacements of reference points reflect the values of displacements in relation to the pole, as well as their mutual displacements. Thus, based on the apparent displacements, it is possible to globally assess the stability of the reference system, as well as identify groups of mutually stable points. It is worth to remembering that the pole is the only point at which zero displacement is most probable. Vectors of the apparent displacements of reference points, as well as their mean errors, depend on the location in relation to the pole. Points located close to the pole are characterised by smaller errors than those further away.

The Author of this paper proposes to assume the assessment of the ratio between the length of the displacement vector $\boldsymbol{D}$ to its mean error $\boldsymbol{m}_{\boldsymbol{D}}$ as the stability criterion, with consideration to point location in relation to the pole.

In general, the proposed criterion may be written in the following form:

$$
\begin{gathered}
D_{i} / m_{D_{i}} \leq k \\
D_{R} \in\left(D_{i}-k m_{D_{i}}, D_{i}+k m_{D_{i}}\right), \text { where: } D_{R}=a d
\end{gathered}
$$

where: $k$ - the multiplication of the mean error of length of the apparent displacement vector,

$\Delta_{R}$ - uniform approximation of lengths of vectors ordered according to distances from the pole, with consideration of their intervals of confidence,

$a-$ the coefficient of the model,

$d$ - the distance between the point and the pole.

Among $s$ possible reference points we select points for which a straight line, determined in the linear regression model, poses the intervals $D_{i} \pm k m_{D i}$.

Coefficients of the model, described by the formula (8) may be estimated by means of a simple regression which utilises a least square method, or by means of a graphical method using uniform approximation.

A detailed process of identifying stable reference points, will be presented using the example of an angular-and-linear network of a barrage.

\section{An example of the proposed method for identifying stable reference points}

The identification of stable reference points is presented here using the example of an angular-and-linear network of the „Włocławek” barrage (Fig.1). The extension of the network has been restricted for the presentation in this paper.

Results for the initial adjustment of observational differences from two cycles of measurements, under the assumption of the potential stability of all reference points, are presented in Table 1. 


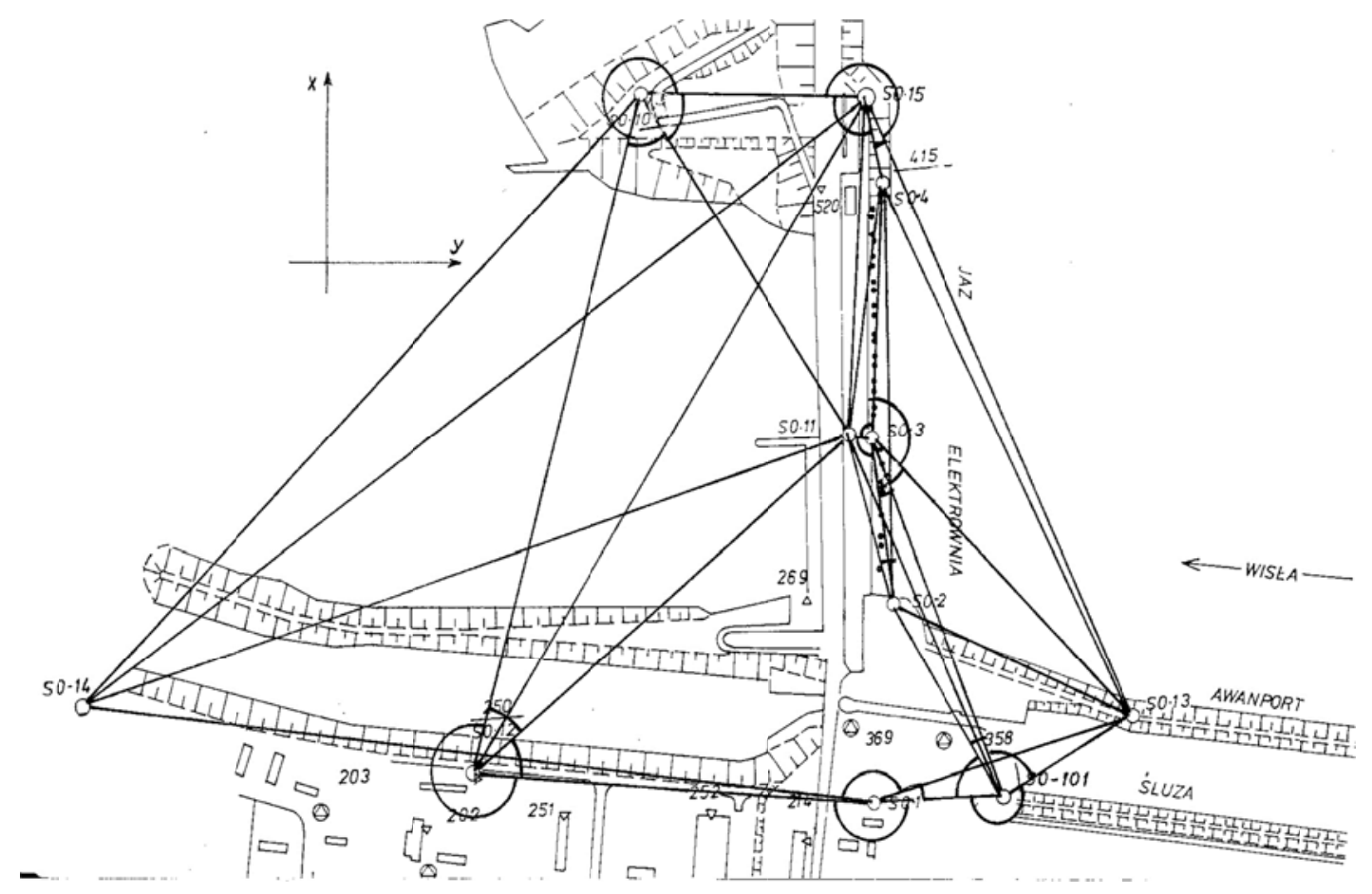

Fig.1. Example of the control horizontal network for a barrage

Table 1. Synthetic presentation of results of initial adjustment of observational differences

\begin{tabular}{|c|c|c|c|c|c|c|c|c|c|c|c|c|}
\hline $\mathrm{Nr}$ & $\begin{array}{c}X \\
{[\mathrm{~m}]}\end{array}$ & $\begin{array}{c}\mathrm{Y} \\
{[\mathrm{m}]}\end{array}$ & $\begin{array}{c}\Delta \mathrm{X} \\
{[\mathrm{mm}]}\end{array}$ & $\underset{[\mathrm{mm}]}{\Delta \mathrm{y}}$ & $\underset{[\mathrm{mm}]}{D}$ & $\begin{array}{c}\mathrm{Az} \\
\text { [g] }\end{array}$ & $\begin{array}{l}\mathrm{m}_{\Delta \mathrm{x}} \\
{[\mathrm{mm}]}\end{array}$ & $\begin{array}{c}\mathrm{m}_{\Delta \mathrm{y}} \\
{[\mathrm{mm}]}\end{array}$ & $\begin{array}{c}\mathrm{m}_{D} \\
{[\mathrm{~mm}]}\end{array}$ & $\frac{|\Delta x|}{m_{\Delta x}}$ & $\frac{|\Delta y|}{m_{\Delta y}}$ & $\underline{\mathrm{D}}$ \\
\hline 1 & 258.2380 & 1216.5191 & 0.41 & 0.64 & 0.76 & 64.1 & 0.51 & 0.35 & 0.37 & 0.8 & 1.8 & 2.0 \\
\hline 2 & 461.3022 & 1224.6608 & 5.71 & -2.63 & 6.29 & 372.5 & 0.46 & 0.59 & 0.44 & 12.4 & 4.4 & 14.2 \\
\hline 3 & 613.1520 & 1218.8691 & -3.42 & -4.40 & 5.57 & 258.0 & 0.38 & 0.42 & 0.46 & 9.0 & 10.6 & 12.1 \\
\hline 4 & 868.0871 & 1218.8591 & -1.76 & -0.71 & 1.90 & 224.2 & 0.33 & 0.55 & 0.41 & 5.3 & 1.3 & 4.7 \\
\hline 10 & 999.9975 & 999.9991 & -0.18 & 1.27 & 1.29 & 108.8 & 0.50 & 0.46 & 0.46 & 0.4 & 2.8 & 2.8 \\
\hline 11 & 614.1448 & 1208.2174 & -2.03 & -2.30 & 3.07 & 254.0 & 0.33 & 0.39 & 0.40 & 6.2 & 6.0 & 7.7 \\
\hline 12 & 280.5485 & 803.3932 & 0.94 & 1.49 & 1.76 & 64.2 & 0.63 & 0.52 & 0.41 & 1.5 & 2.8 & 4.3 \\
\hline 13 & 332.4555 & 1482.0261 & 0.21 & 1.06 & 1.08 & 287.5 & 0.38 & 0.39 & 0.41 & 0.6 & 2.7 & 2.6 \\
\hline 14 & 393.2556 & 366.5928 & 0.04 & 2.88 & 2.88 & 99.1 & 0.74 & 0.58 & 0.57 & 0.1 & 5.0 & 5.0 \\
\hline 15 & 982.1122 & 1217.7693 & -0.16 & 2.30 & 2.31 & 304.5 & 0.36 & 0.39 & 0.39 & 0.4 & 5.9 & 5.9 \\
\hline 101 & 251.8720 & 1367.7920 & 0.24 & 0.40 & 0.47 & 65.9 & 0.31 & 0.47 & 0.47 & 0.8 & 0.9 & 1.0 \\
\hline \multicolumn{3}{|c|}{$\sigma_{0}=0,84$} & \multicolumn{4}{|c|}{$\Sigma \mathrm{m}^{2} \cdot{ }_{\Delta x, \Delta y, D}$ (for ref. points) } & 2,33 & 2,44 & 2,12 & & & \\
\hline
\end{tabular}

It turns out that only points 1 and 101 meet the criterion of stability in the form:

$$
|\Delta X| / m_{\Delta X} \leq 2 \text { and }|\Delta Y| / m_{\Delta Y} \leq 2 \text { or } D / m_{D} \leq 2 .
$$

It may be also noticed that the criterion $D / m_{D} \leq 2$ is more severe than inspecting $|\Delta X| / m_{\Delta X} \leq 2$ and $|\Delta Y| / m_{\Delta Y} \leq 2$. Besides the mean errors of components vectors of displacements are the so-called positional characteristics of the accuracy. When searching for mutually stable points, the process should start from an assumption that the multiplicity of the mean error of the component of the vector of displacement is $k=1$. 
In practice, the index of importance should be gradually increased, aiming to assign $k=1$ to approximately $60 \%$ of reference points and $k=2$ for $95 \%$ of reference points etc. Assumptions concerning the expected number of points in the future and their distribution in relation to an investigated object should be also considered.

Figure 2-5 presents successive stages of identification of stable reference points on the basis of lengths of apparent vectors and their mean errors. Considering the dependence of the lengths of vectors and their mean errors on the location in relation to the pole - to determine the set of mutually stable points, we will use the straight line regression for the lengths of vectors located proportionally to their distances from the pole.

After elimination of points 11,3,2 from the set of "stable" reference points, readjustment of observational differences should be performed and then obtained lengths of vectors and their mean errors should be analysed similarly to the stages 1 and 2.

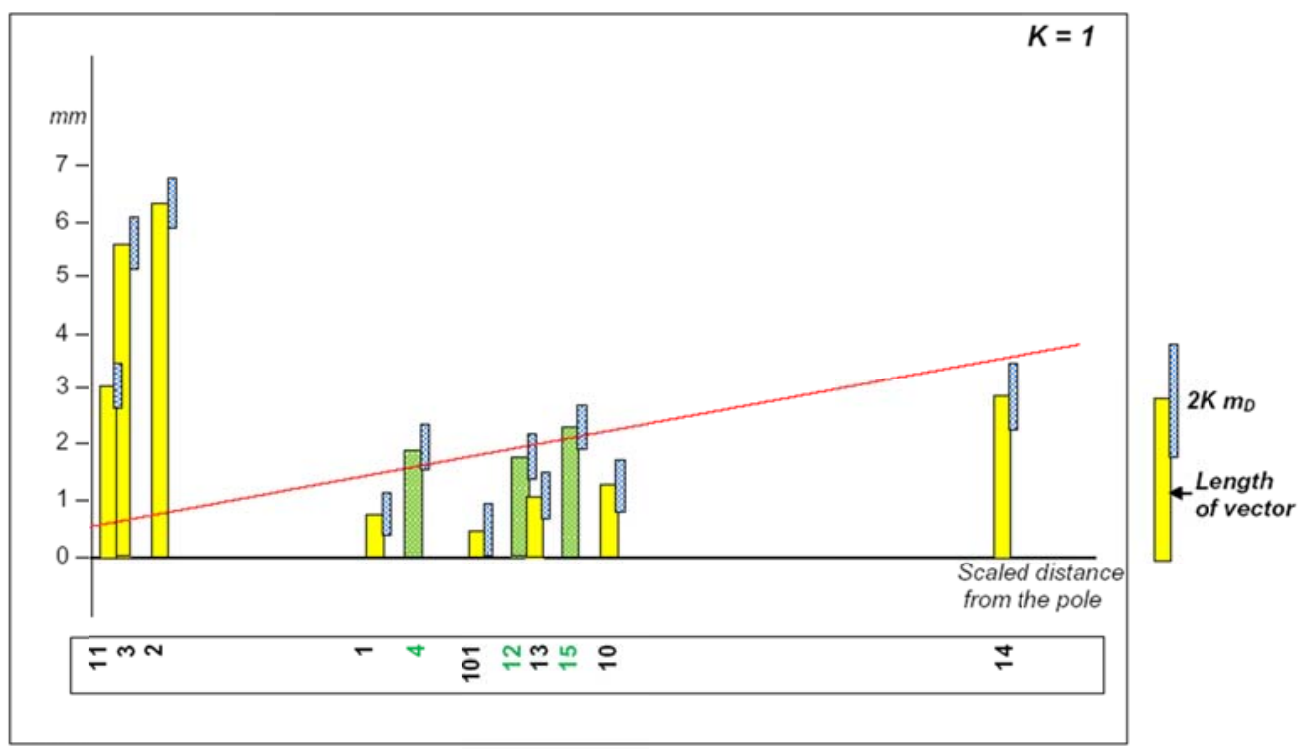

Fig. 2. Stage 1 of identification of stable reference points for the coefficient of multiplicity of the mean errors of the vector length $\mathrm{k}=1$.

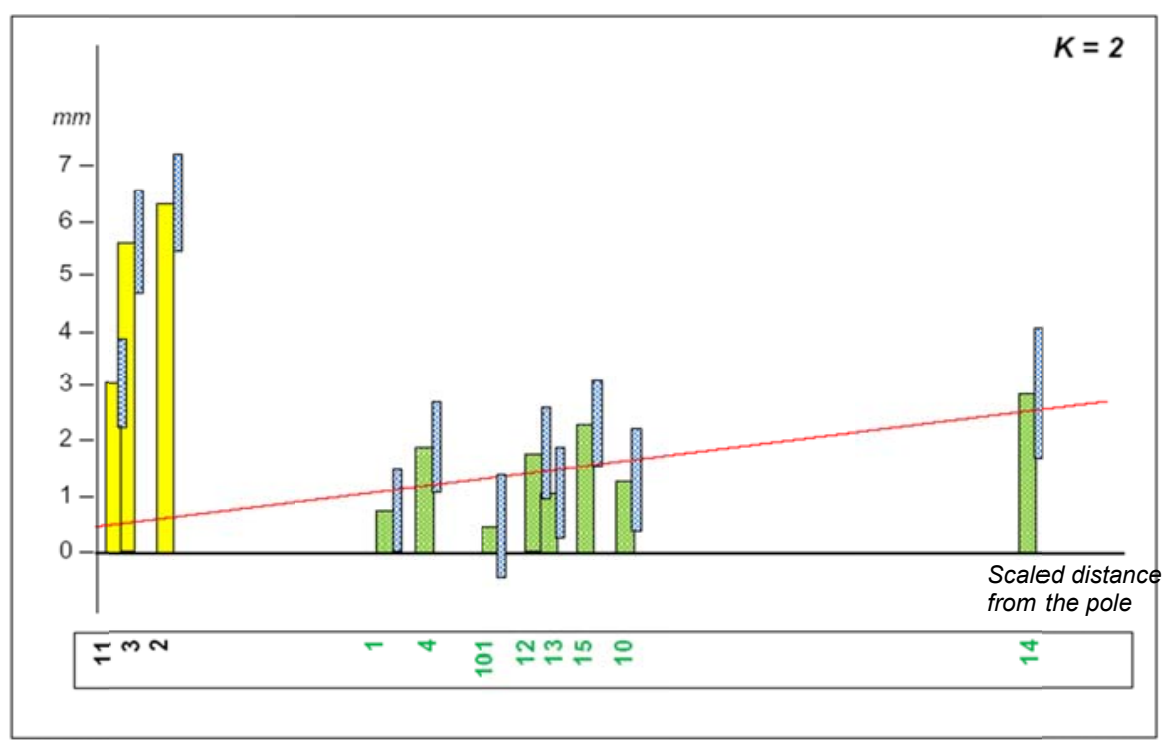

Fig. 3. Stage 2 of the process of identification of stable reference points for $k=2$. 


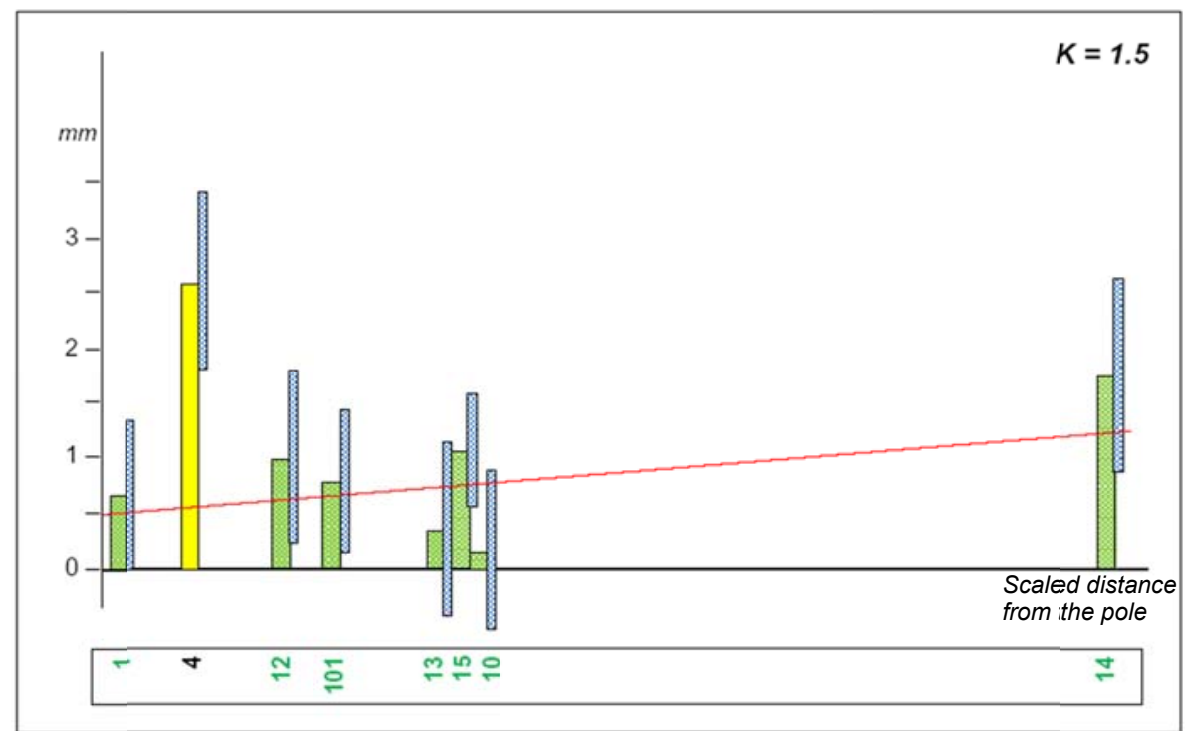

Fig. 4. Stage 3 of the process of identification of stable reference points for $k=1.5$.

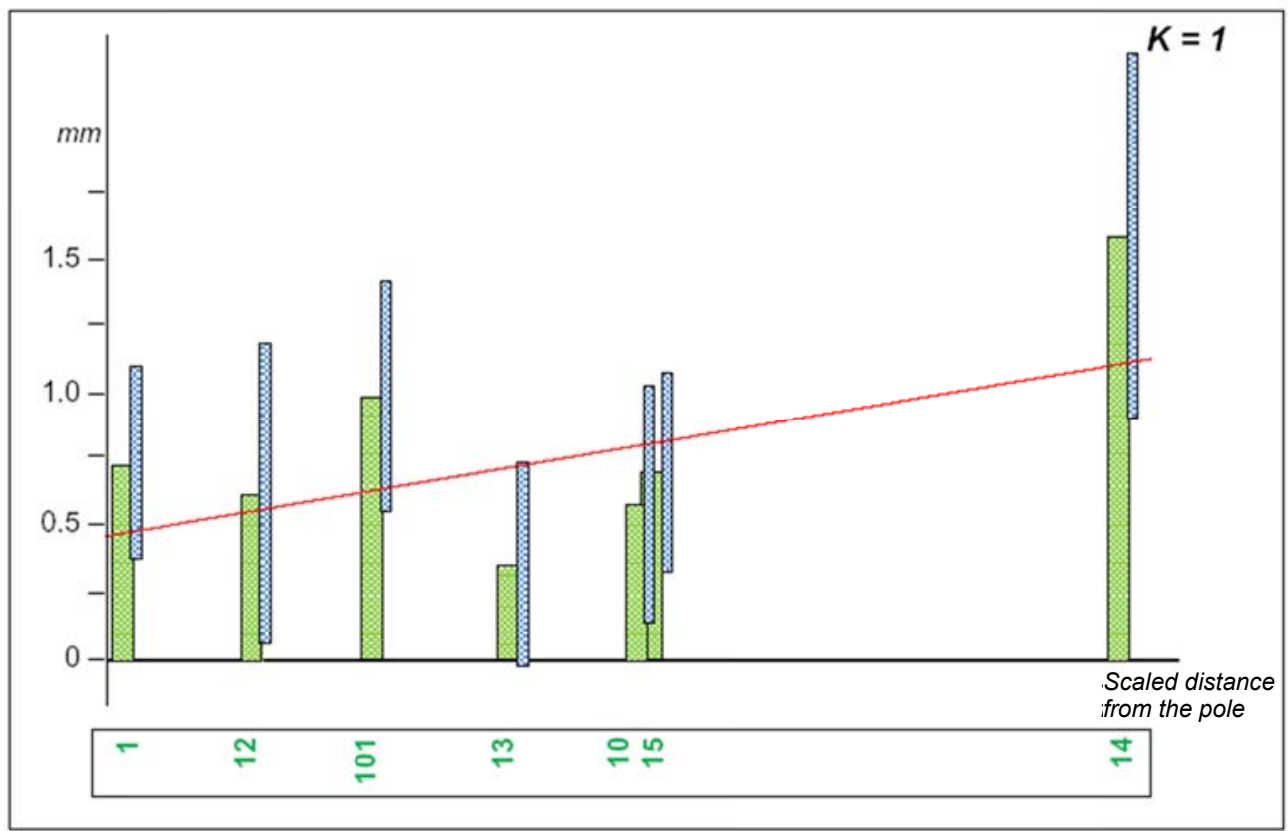

Fig. 5. Stage 5 - the final stage.

It may be seen from Fig.5, that for the index of multiplicity of the mean error $k=1$, lengths of vectors for residual displacements of reference points does not exceed the interval of uncertainty. It turns out that the properties of adjustment with consideration of Helmert conditions lengths of vectors for mutually stable reference points may, depending on their locations, exceed the assumed multiplicity of the mean error of determination (see point 14).

Detailed results of the final stage of calculations of displacements are presented in Table 2. 
Table 2. Results of the final adjustment of observational differences

\begin{tabular}{|c|c|c|c|c|c|c|c|c|}
\hline No $p$. & $\begin{array}{c}\Delta \mathrm{X} \\
{[\mathrm{mm}]}\end{array}$ & $\begin{array}{c}\Delta y \\
{[\mathrm{~mm}]}\end{array}$ & $\begin{array}{c}D \\
{[\mathrm{~mm}]}\end{array}$ & $\begin{array}{l}\mathrm{Az} \\
{[\mathrm{g}]}\end{array}$ & $\begin{array}{c}\mathrm{m}_{\Delta \mathrm{x}} \\
{[\mathrm{mm}]}\end{array}$ & $\begin{array}{c}\mathrm{m}_{\Delta \mathrm{y}} \\
{[\mathrm{mm}]}\end{array}$ & $\begin{array}{c}\mathrm{m}_{D} \\
{[\mathrm{~mm}]}\end{array}$ & \\
\hline 1 & 0,26 & $-0,68$ & 0,73 & 323,7 & 0,48 & 0,31 & 0,36 & Ref.p \\
\hline 2 & 5,58 & $-4,05$ & 6,89 & 360,0 & 0,56 & 0,69 & 0,54 & \\
\hline 3 & $-3,56$ & $-5,89$ & 6,88 & 265,4 & 0,48 & 0,53 & 0,59 & \\
\hline 4 & $-1,90$ & $-2,32$ & 3,00 & 256,2 & 0,42 & 0,65 & 0,62 & \\
\hline 10 & $-0,42$ & $-0,40$ & 0,58 & 248,4 & 0,48 & 0,40 & 0,44 & Ref. \\
\hline 11 & $-2,17$ & $-3,79$ & 4,37 & 266,9 & 0,39 & 0,47 & 0,48 & \\
\hline 12 & 0,60 & 0,16 & 0,62 & 16,2 & 0,63 & 0,50 & 0,56 & Ref.p. \\
\hline 13 & 0,20 & $-0,29$ & 0,35 & 137,6 & 0,36 & 0,40 & 0,38 & Ref.p. \\
\hline 14 & $-0,51$ & 1,50 & 1,58 & 120,8 & 0,69 & 0,57 & 0,68 & Ref.p \\
\hline 15 & $-0,30$ & 0,64 & 0,70 & 328,3 & 0,38 & 0,38 & 0,37 & Ref.p. \\
\hline 101 & 0,17 & $-0,91$ & 0,93 & 311,7 & 0,31 & 0,44 & 0,43 & Ref.p. \\
\hline \multicolumn{2}{|c|}{$\sigma_{0}=0,8$} & \multicolumn{3}{|c|}{$\sum \mathrm{m}^{2}{ }_{\Delta x, \Delta y, \mathrm{D}}$ (for ref. points) } & 1,69 & 1,32 & 1,57 & \\
\hline
\end{tabular}

In large geodetic networks diversification of mean errors of displacements, depending on a point location in relation to the pole and the network geometry, would be more clearly visible.

In the case where big displacements of similar lengths occur in the initials stages of identification, the process of identification should be extended to analysis the rotation of particular vectors. Therefore, Tables 1 and 2 contain the list of azimuths of vectors of apparent displacements of reference points.

The final set of reference points depends on the assumed coefficient $\boldsymbol{k}$ /the multiplicity of the mean error of length of a vector of apparent displacement/.

In the case of surveys of displacements the assessment of the accuracy of such displacements is also important, similarly to values of displacements. It may be easily noticed that values of residual displacements of reference points are not transferred to the mean error of displacements of the pole or on the mean errors of displacements of controlled points. It is definitely the disadvantage of the method of calculation of displacements with consideration of free adjustment conditions.

In the process of adjustment performed using free conditions the mean error „0" of displacements of the pole is always zero. It is not the result of the network geometry, the number of reference points or the accuracy of performed observations.

Therefore two questions arise:

- Should the mean error of matching be considered in the process of assessing the accuracy of vectors components of displacements of apparent displacements of reference points?

- Should the mean error of matching be considered in the process of assessing of the accuracy of components of vectors of displacements of controlled points?

\section{Conclusions}

The lengths of vectors and their mean errors deliver sufficient information for assessment point stability in horizontal networks.

In the process of calculating displacements with consideration to free adjustment the pole is the only point which zero displacement is mostly probable. 
Apparent displacements of reference points and displacements of controlled points reflect displacements of those points in relation to the pole.

For the assessment of point stability, based on apparent displacements obtained during the process of calculations performed with consideration of free adjustment conditions, distances of points from the centre of gravity of the network should be considered.

In the case where a group of points of "the same" apparent displacements is detected, the proposed identification process should be amended with the analysis of rotation of vectors of apparent displacements.

Clarification of the process of identification of stable reference points is of extreme importance in control networks on large areas, or when the controlled object is not located at the centre of a set of reference points.

Including stable reference points into the process of calculations of displacements, by a process of identification, we can monitor the influence of inclusion or exclusion of a point into the database on the values of displacements of controlled points.

The high efficiency of the proposed method of identification of stable reference points has been confirmed by the results of calculations performed for more than ten control networks, developed by Author of this paper. This method of examination of reference points stability is an integral part of the numerical programs for evaluation of horizontal displacement measurements (Malarski and Tomiczak, 1996).

An important disadvantage of calculating of displacements with consideration to free adjustment conditions, is ignoring the values of residual displacements of reference points, in the process of assessing the accuracy of displacements of controlled points.

\section{References}

Laudyn, I., (1985). Rozważania nad układem odniesienia do geodezyjnego wyznaczania przemieszczeń (Studies on a set of reference points for geodetic determination of displacements). Prace Instytutu Geodezji i Kartografii, t. XXXII, z. 1-2.

Lazzarini, T. (1977). Geodezyjne pomiary przemieszczeń budowli i ich otoczenia. PPWK.

Malarski, R. \& Tomiczak, E., (1996). Instrukcje obsługi programów numerycznych do opracowania pomiarów przemieszczeń poziomych $i$ pionowych (Manuals of numerical programs for evaluation of horizontal and vertical displacement measurements). Politechnika Warszawska, Instytut Geodezji Gospodarczej.

Świątek, K. \& Wiśniewski, Z., (1983). Wyrównanie niezależnych sieci geodezyjnych oraz algorytmizowanie obliczeń (Adjustment of independent geodetic nets and algorithmization of calculations), Geodezja i Kartografia, tom XXXII, z.2.

\section{Authors:}

Ryszard Malarski ${ }^{1)}$, r.malarski@gik.pw.edu.pl

1) Chair of Engineering Geodesy and Control-Measuring Systems,

Faculty of Geodesy and Cartography,

Warsaw University of Technology,

PI. Politechniki 1, 00-661 Warsaw, Poland 